\title{
Linear DNA plasmids from Pichia etchellsii, Debaryomyces hansenii and Wingea robertsiae
}

\author{
Yu-Sheng Cong, ${ }^{1}$ David Yarrow, ${ }^{2}$ Yu-Yang $\mathrm{Li}^{3}$ and Hiroshi Fukuhara'
}

Author for correspondence: Hiroshi Fukuhara. Tel: +331698630 63. Fax: +33169869429.

1 Institut Curie, Section de Biologie, Batiment 110, Centre Universitaire Paris XI, Orsay 91405 France

2 Centraalbureau voor Schimmelcultures, Yeast Division, 2628 BC Delft, The Netherlands

${ }^{3}$ Genetics Institute, Fudan University, Shanghai 200433, China

\begin{abstract}
Linear DNA plasmids were found in the following yeasts: four strains of Kluyveromyces lactis, one of Debaryomyces hansenii, one of Wingea robertsiae and four of Pichia etchellsii. In each case, the plasmids were present as a pair of DNA molecules of different sizes. The plasmids of $K$. lactis strains were associated with a killer activity and their structure was similar to the known killer plasmids PGKL1 and 2. The plasmids from the other three species were different from pGKL plasmids and showed no killer activity against the yeast species tested so far. In all cases, the linear molecules possessed terminal (probably inverted) repeats and their $5^{\prime}$ ends had a protected structure insensitive to $\lambda$ exonuclease, while the $3^{\prime}$ ends were accessible to exonuclease III. All these strains could be efficiently cured of the plasmids by ultraviolet irradiation. The plasmids from D. hansenii (PDH1A and B) and from $W$. robertsiae (pWR1A and B) shared related sequences with some of the $K$. lactis killer plasmid genes (encoding the supposed DNA polymerases, RNA polymerase and the chitinase), suggesting related genome organization of these plasmids. The pair of plasmids from P. etchellsii (PPE1A and B) appear to be a distantly related member of the group. This pair showed no sequence homology with other plasmids, except weak homology with the putative RNA polymerase gene of pGKL2. None of the plasmids contained the sequences homologous to ORF3 and ORF4 of pGKL1 encoding the toxin resistance determinant and the toxin $\gamma$ subunit, respectively.
\end{abstract}

Keywords: Pichia etchellsii, Debaryomyces hansenii, Wingea robertsiae, linear DNA plasmids, yeast plasmids

\section{INTRODUCTION}

The linear plasmids pGKL1 and pGKL2 from the Kluyyeromyces lactis strain IFO 1267 (NRRL Y-1140, CBS 2359) (Gunge et al., 1981; Wésolowski et al., 1982) were the first of a new class of plasmids in yeast. These plasmids, present in pairs, confer a killer phenotype on the host cell. While pGKL2 can replicate in the absence of pGKL1, the latter is maintained only in the presence of the former. Sequence studies (Tommasino et al., 1988; Wilson \& Meacock, 1988) suggested that the transcription of plasmid genes depends on the putative RNA polymerase encoded by pGKL2. The presence of terminal inverted repeats in both plasmids (Sor et al., 1983) and the blocked $5^{\prime}$ ends with covalently attached proteins (Kikuchi et al., 1984; Stam et al., 1986) suggested that the plasmids have a protein-primed mode of replication analogous to that of adenoviruses or bacteriophage $\phi 29$. Linear DNA plasmids with related structures have also been found in many filamentous fungi (reviewed by
Meinhardt et al., 1990). All of these plasmids from filamentous fungi seem to replicate within mitochondria, whereas the linear plasmids found in yeast are thought to replicate in the cytoplasm.

It is not known whether linear plasmids of the pGKL type are widely distributed in the yeasts. Only pSK1, closely related to pGKL2, was known in Saccharomyces kluyverii (Kitada \& Hishinuma, 1987). A recent survey involving most of the 600 yeast species (in preparation) indicated that linear DNA plasmids, in contrast to the doublestranded RNA plasmids, are not frequent. DNA plasmids which are assumed to be or confirmed to be linear were found in less than a dozen of the 1400 strains examined. We describe here the properties of some of these linear plasmids and compare them with the killer DNA plasmids. 


\section{METHODS}

Yeast strains. Most strains described here are stocks of the Centraalbureau voor Schimmelcultures (CBS), Yeast Division, Delft, The Netherlands. Kluyveromyces lactis strain NRRL Y1115 was obtained from Dr C. P. Kurtzman (Northern Regional Research Laboratory, Peoria, Illinois, USA). Species names are, in most cases, those adopted in the CBS catalogue $(1990$ edition). Yeast was grown in a glucose complete medium [ $2 \%$ $(\mathrm{w} / \mathrm{v})$ glucose, $1 \%(\mathrm{w} / \mathrm{v})$ yeast extract (Difco) and $1 \%(\mathrm{w} / \mathrm{v})$ Bactopeptone (Difco)] at $27^{\circ} \mathrm{C}$.

Detection of plasmids in whole cell minilysates. A 1-2 mmsized colony was suspended in $18 \mu \mathrm{l}$ Zymolyase solution (Zymolyase 20T, Kirin Breweries, Tokyo; $4 \mathrm{mg} \mathrm{ml}^{-1}$ in $50 \mathrm{mM}$ Tris $/ \mathrm{HCl}, \mathrm{pH} 8,5 \mathrm{mM}$ EDTA) and incubated at $30^{\circ} \mathrm{C}$ for $1 \mathrm{~h}$. One microlitre $5 \%(\mathrm{w} / \mathrm{v})$ SDS and $3 \mu$ l proteinase $\mathrm{K}$ (Boehringer, $2 \mathrm{mg} \mathrm{ml}^{-1}$ ) were added and the suspension was further incubated for $1 \mathrm{~h}$ at $65^{\circ} \mathrm{C}$. After the addition of $5 \mu$ l blue dye solution (colour marker for conventional electrophoresis), the lysates were microcentrifuged for $3 \mathrm{~min}$ and $15 \mu \mathrm{l}$ of the supernatant was electrophoresed in $0.6 \%$ agarose gel. To visualize the presence of plasmids, the gel was stained with ethidium bromide $\left(0.5 \mu \mathrm{g} \mathrm{ml}^{-1}\right)$ and photographed through a yellow filter under ultraviolet light.

Purification of plasmids. The cells from $100 \mathrm{ml}$ culture were lysed essentially as described above, but on a larger scale. Only the amount of enzyne was reduced to the minimum required (variable for each species), for reasons of economy. The bands of plasmid DNA were excised, electroeluted, and adsorbed on a DEAE-cellulose column. The DNA was eluted with $2 \mathrm{M} \mathrm{NaCl}$ and precipitated with ethanol. The precipitates were dried and dissolved in $1 \mathrm{mM}$ Tris/ $\mathrm{HCl}, \mathrm{pH} 8,0 \cdot 1 \mathrm{mM}$ EDTA.

Assay of killer activity. Killer activity of yeast colonies was tested against three tester strains: Saccharomyces cerevisiae $5 \mathrm{X} 47$ (from Dr R. Wickner, National Institute of Health, Bethesda, USA), K. lactis 2360/7 (Wésolowski et al., 1982) and Candida glabrata CBS 138. The latter has been reported to be highly sensitive to a wide range of yeast killer toxins (Hara, 1985). The procedure was as follows. Ten microlitres of a fresh culture of a tester strain was mixed with $10 \mathrm{ml}$ molten glucose complete medium with $2 \%(\mathrm{w} / \mathrm{v})$ Oxoid agar no. 1 (kept at $45^{\circ} \mathrm{C}$ ). Colonies of killer strains to be tested were spotted or replicaplated onto the solidified agar plate and incubated at $20^{\circ} \mathrm{C}$ for $3 \mathrm{~d}$. Killer activity was evaluated from the diameter of the zone of growth inhibiton.

Curing of plasmids. Fresh cultures were diluted with water to a density of about $10^{7}$ cells $\mathrm{ml}^{-1}$ and exposed to ultraviolet light at $1 \mathrm{~J} \mathrm{~m}^{-2} \mathrm{~s}^{-1}$ for $50 \mathrm{~s}$ (cellular lethality about $60-75 \%$ ). Cells were plated on complete glucose plates, and randomly chosen colonies were examined for the presence or absence of plasmids by mini-lysate analysis.

DNA blot hybridization. After agarose electrophoresis of the colony lysates, DNA bands were transferred onto a sheet of nitrocellulose membrane, and hybridized with radioactive DNA probes at $65^{\circ} \mathrm{C}$ overnight in a solution containing $0.6 \mathrm{M} \mathrm{NaCl}$, $0.06 \mathrm{M}$ sodium phosphate, $\mathrm{pH} 7$ and $1 \%$ SDS. The membrane was washed at room temperature in a solution containing $0.3 \mathrm{M} \mathrm{NaCl}, 0.03 \mathrm{M}$ sodium phosphate and $0.1 \% \mathrm{SDS}$. The membrane was dried, and the hybrids were detected by autoradiography.

\section{RESULTS}

\section{K. lactis plasmids}

The previously reported linear DNA plasmids, pGKL1 and pGKL2, are associated with the killer character of the strain IFO 1267 (NRRL Y-1140, CBS 2359) (Gunge et al., 1981). We found similar plasmids in four of the 31 strains of $K$. lactis isolated from various geographical origins. These strains are CBS 1065 (plasmids pKL2A and B), CBS 5618 (plasmids pKL3A and B), CBS 8043 (plasmids pKL4A and B) and NRRL Y-1115 (plasmids pKL5A and $\mathrm{B})$. The letters A and B stand for the small and the large components of each plasmid pair, respectively. No other $K$. lactis strains examined contained linear plasmids (CBS $141,683,739,743,762,845,1067,1797,2103,2360,2619$, 2620, 2621, 2877, 2896, 3010, 4372, 4574, 4627, 5669, $5670,6076,6170,6315,6747$ and NRRL Y-1114). The above four strains all showed a killer activity, except Y1115 which was a very weak killer. After purification, these plasmids showed an electrophoretic mobility identical to the pGKL plasmids. The small component (A) of each pair of plasmids hybridized specifically with labelled pGKL1 plasmid, and the large component (B) hybridized only with pGKL2. Analysis of a few restriction sites led us to conclude that these $K$. lactis plasmids were similar, if not identical, to pGKL killer plasmids (data not shown). Besides $K$. lactis strains, 49 strains representing most of the CBS collection of $K$. marxianus were also examined, but no plasmids were found by the mini-lysate procedure described above. It should be noted that very large plasmids may have escaped detection in the electrophoretic procedure used.

\section{Plasmids from three other yeast species}

Three pairs of new plasmids were found.

(i) Debaryomyces hansenii (CBS 770) contained two plasmids which we named pDH1A $(8.2 \mathrm{~kb})$ and $\mathrm{pDH} 1 \mathrm{~B}$ $(14 \cdot 4 \mathrm{~kb})$. No plasmids were detected in the other $24 \mathrm{D}$.

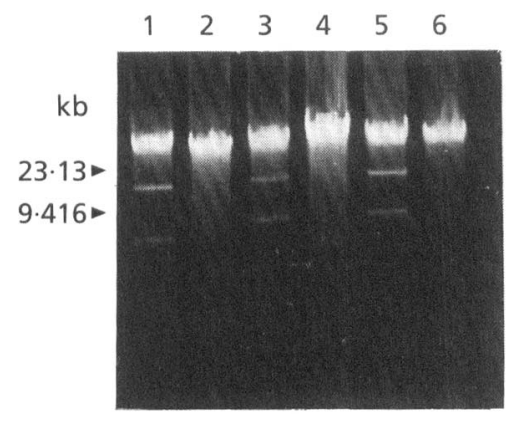

Fig. 1. Detection of plasmids and curing by ultraviolet light. A single colony lysate of each strain was electrophoresed in agarose gel. DNA was stained with ethidium bromide and photographed. For each species, a plasmid-containing clone (lanes 1, 3, 5) and a UV-cured clone (lanes 2, 4, 6) are shown. Lanes: 1 and 2, P. etchellsii; 3 and 4, D. hansenii; 5 and 6, W. robertsiae. Arrows indicate the size and position of molecular mass markers ( $\lambda$ DNA HindIII digest). 
Plasmids PWR1A and pWR1B from W. robertsiae CBS 6693

Plasmids pDH1A and pDH1B from D. hansenii CBS 770

Plasmids pPE1A and PPE1B from P. etchellsii CBS 2011

PWR1A $8.3 \mathrm{~kb}$

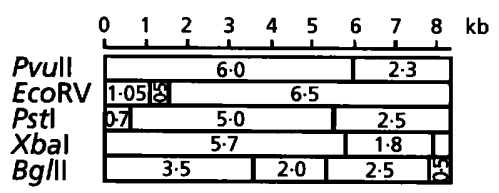

PWR1B $14.6 \mathrm{~kb}$

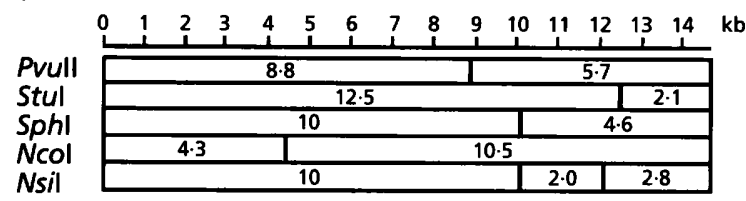

pDH1A $8 \cdot 2 \mathrm{~kb}$

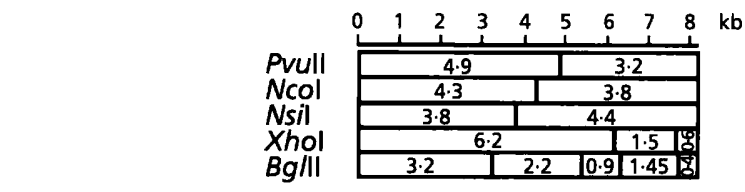

pDH1B $14.4 \mathrm{~kb}$

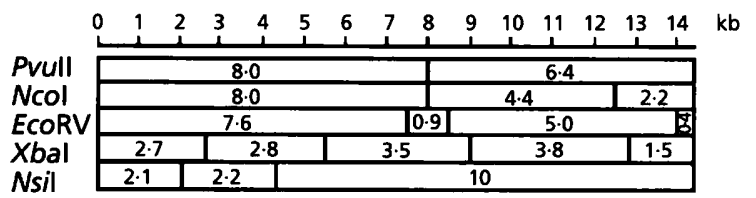

PPE1A $6.7 \mathrm{~kb}$

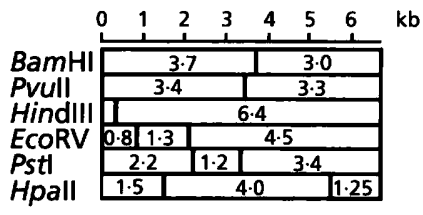

PPE1B $12.8 \mathrm{~kb}$

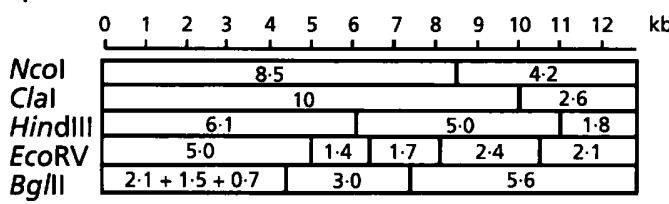

Fig. 2. Restriction maps of plasmids. Each purified plasmid was digested with indicated restriction enzymes individually and in different combinations. The linear maps were deduced only from these digestion data. The positions of the terminal fragments were confirmed by end label experiments shown in Fig. 4. bansenii strains tested (CBS 116, 767, 788, 789, 790, 792, $949,1098,1101,1102,1103,1123,1124,1791,1796,1962$, $2333,2844,5139,5230,5307,5572,6958$ and 6960).

(ii) Wingea robertsiae (CBS 6693) contained two plasmids designated pWR1A $(8.3 \mathrm{~kb})$ and pWR1B (14.6 kb). Another strain of $W$. robertsiae (CBS 2934, type strain) did not carry any plasmids.

(iii) Pichia etchellsii (CBS 2011) also contained two plasmids, pPE1A $(6.7 \mathrm{~kb})$ and pPE1B $(12.8 \mathrm{~kb})$. Three other isolates (CBS 2012, 5603 and 6823) contained similar plasmids ( $\mathrm{PPE} 2 \mathrm{~A}$ and $\mathrm{B}, \mathrm{pPE} 3 \mathrm{~A}$ and $\mathrm{B}$, and $\mathrm{pPE} 4 \mathrm{~A}$ and $\mathrm{B}$, respectively). CBS 6823 contained, in addition, a plasmid of an apparent size of $4.5 \mathrm{~kb}$. This is most probably double-stranded RNA because it was sensitive to high doses of RNase A. Only one strain (CBS 5519) was devoid of plasmids. The pPE2-pPE4 series plasmids were identical to $\mathrm{pPE} 1 \mathrm{~A}$ and $\mathrm{pPE} 1 \mathrm{~B}$ according to a few restriction digestion experiments. These plasmids were therefore not studied further.
Fig. 1 shows the new linear DNA plasmids as detected by electrophoresis of the colony lysates. It was found that these plasmids could be readily eliminated by ultraviolet irradiation of the host cultures. At a dose of $50 \mathrm{~J} \mathrm{~m}^{-2}$, more than $90 \%$ of cells lost both large and small plasmids, without detectable change in growth phenotype.

The plasmids were excised from the preparative gels and purified. Restriction maps and deduced molecular masses are shown in Fig. 2. The plasmid maps were different from each other, and from the pGKL plasmids of $K$. lactis.

\section{Subcellular localization of the plasmids}

The plasmids from $D$. bansenii, $W$. robertsiae and $P$. etchellsii do not seem to be associated with mitochondria. Preliminary experiments showed that crude mitochondrial preparations were not enriched in these plasmids (often undetectable), which suggests that they occur in the cytoplasm as in the case of pGKL plasmids (Stam et al., 1986; Gunge, 1986). Fluorescence staining of cytoplasmic 


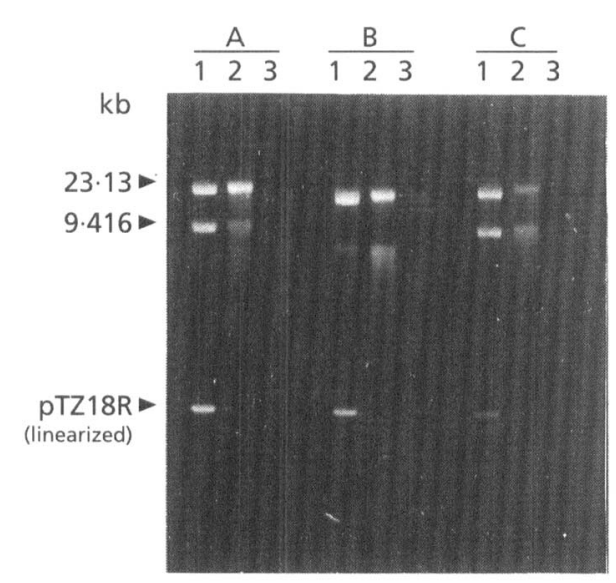

Fig. 3. Accessibility of exonucleases to the plasmid termini. About $50 \mathrm{ng}$ each of purified large and small components of each pair of plasmids was artificially mixed, and treated with either 5 units $\lambda$ exonuclease (Gibco) or $\mathbf{5 0}$ units exonuclease III (Gibco), at $37^{\circ} \mathrm{C}$ for $1 \mathrm{~h}$ according to the enzyme supplier's protocols. In the mixture, the circular plasmid PTZ18R (Pharmacia) linearized by EcoRI digestion was also included as an internal control. Digested DNA was electrophoresed in $0.8 \%$ agarose gel and visualized by ethidium bromide staining under ultraviolet light. A, pWR1A+1B; B, pPE1A+1B; C, pDH1A+1B. Lanes: 1 , no enzyme treatment; 2 , treated with $\lambda 5^{\prime}$ exonuclease; 3 , treated with $3^{\prime}$-exonuclease III.

particles could not give an unambiguous answer to the question because of the presence of mitochondrial DNA which, unlike in the case of $S$. cerevisiae, could not be eliminated from these yeast species. The question of cytoplasmic localization remains to be examined in more detail.

\section{Termini of the linear plasmids}

Linear genomes adopt various forms of terminal structure to complete the replication of their $5^{\prime}$ ends. In the case of pGKL plasmids, $5^{\prime}$ ends are associated with a protein which is probably used to initiate the replication. Some linear mitochondrial DNAs have no terminally attached protein, but have a closed terminal loop linking the complementary strands at each end of the genome (Dinouel et al., 1993). We therefore examined the terminal structure of the linear plasmids by enzymic digestion of the termini (Fig. 3). Exonuclease III could digest the DNA completely, indicating that the $3^{\prime}$ ends were open and not protruding. In contrast, $\lambda$ exonuclease (5'exonuclease) was unable to attack the DNA. Under the same conditions, linearized circular plasmid pTZ18 (EcoRI digest) was sensitive to both exonucleases. It is therefore likely that the $5^{\prime}$ ends have a blocked structure as in the pGKL plasmids.

\section{Left and right termini share a homologous sequence}

In many linear genomes the termini are made of inverted repeats (e.g. adenovirus, $K$. lactis killer DNA, bacteriophage $\phi 29$, S1 and S2 plasmids of chloroplasts) or direct repeats (e.g. bacteriophage T7, Pbysarum mitochondrial
DNA). We examined whether the right and left termini of the linear plasmids shared any common sequences.

A terminal restriction fragment from each plasmid was isolated and labelled by random-priming. Alternatively the $3^{\prime}$ termini of the whole genome were directly labelled by fill-in synthesis by Klenow enzyme, then the labelled terminal restriction fragments were isolated. The latter labelling experiments could identify the terminal fragments of the linear genomes, confirming the maps deduced from the restriction site analysis. Each labelled fragment was used as a hybridization probe to see whether it hybridized with the other end of the genome. This was found to be the case for the large and small components of all the plasmid pairs (Fig. 4). The results show that each of these linear DNAs has homologous sequences at the right and left ends, although the length and orientation of the terminal repeats remain to be determined by sequencing. Within a given pair of plasmids, the terminal sequences were not homologous between the large and small components.

\section{The new plasmids contain some sequences that are homologous to the killer DNA of $K$. lactis}

To examine possible relatedness of the plasmids to one another and to the $K$. lactis pGKL plasmids, each of the new plasmids was labelled and hybridized pairwise with unlabelled plasmid DNA as shown in the examples in Fig. 5. Hybridization experiments were carried out under moderately stringent conditions of hybridization $(0.6 \mathrm{M}$ $\mathrm{Na}^{+}, 65^{\circ} \mathrm{C}$ ), considering the low GC content of the plasmid DNAs (less than $20 \%$ as estimated from their buoyant density). The results are summarized in Table 1.

pPE1 plasmids did not hybridize to a significant extent with any of the plasmids tested. In contrast, pDH1 and pWR1 DNAs hybridized with each other and also with pGKL plasmids. The smaller components ( $\mathrm{pDH} 1 \mathrm{~A}$ and pWR1A) specifically hybridized with the small killer plasmid pGKL1 whilst the large components (pDH1B and $\mathrm{pWR} 1 \mathrm{~B}$ ) hybridized only with the large killer plasmid pGKL2.

\section{Possible nature of the plasmid genes}

The above results suggested that pPE1 plasmids are only distantly related, if at all, with pGKL plasmids, while pDH1 and pWR1 have components clearly related to those of the killer plasmids. Moreover, the fact that the small plasmid components specifically hybridized with pGKL1 whilst the large components only hybridized with PGKL2, suggested that all these plasmids may share a gene organization analogous to the $\mathrm{pGKL}$ double plasmid system. We examined, therefore, which pGKL plasmid genes were present in the new plasmids.

pGKL1 DNA of the killer system has four open reading frames (ORF1-ORF4) (Hishinuma et al., 1984; Stark et al., 1984; Stark, 1988; Sor \& Fukuhara, 1985). The functions of each of these ORFs are reasonably well established (reviewed by Stark et al., 1990). pGKL2 DNA has 10 ORFs (ORF1-ORF10) (Tommasino et al., 1988), 


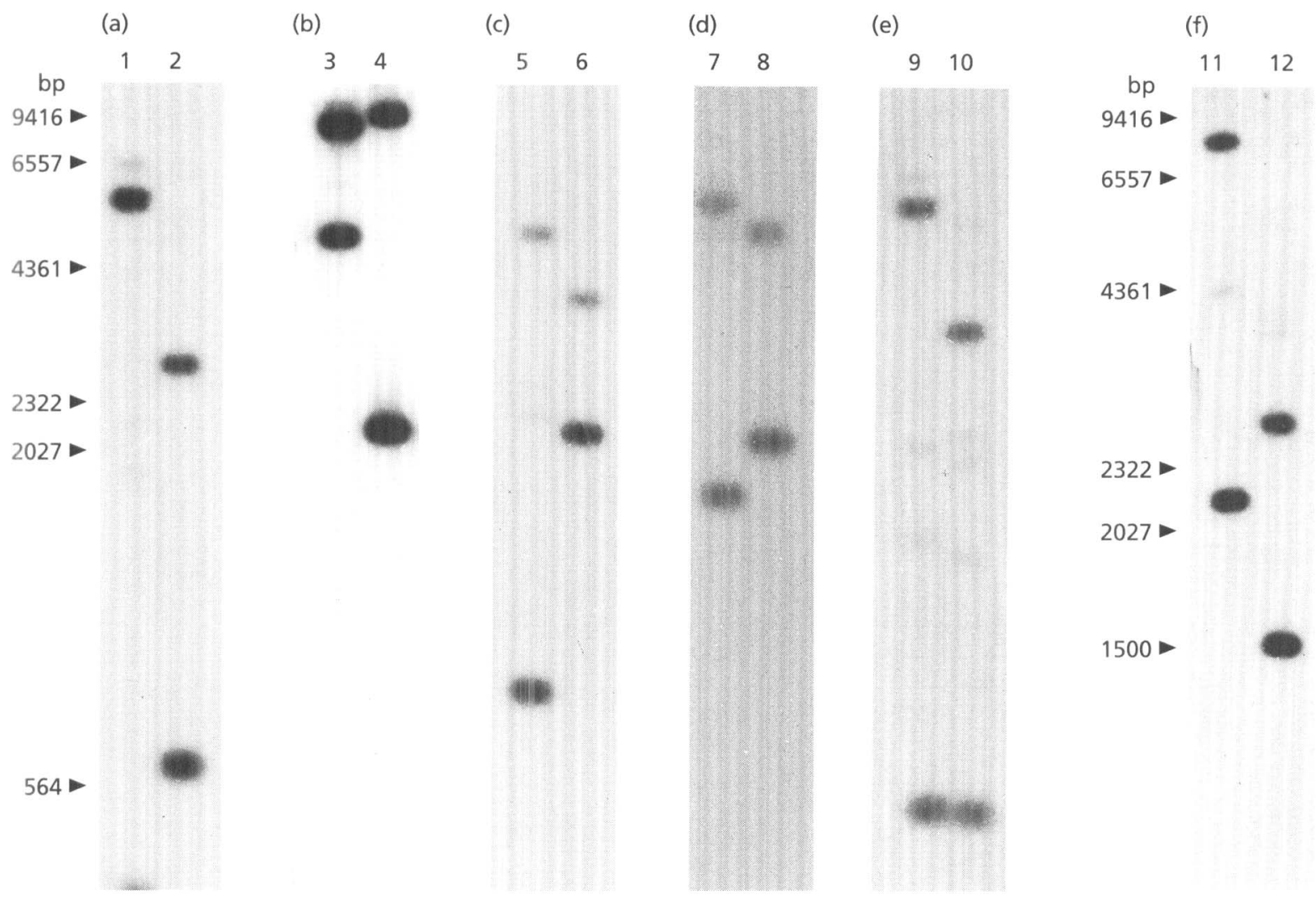

Fig. 4. Terminal repeats in the linear DNA plasmids. The panels (a)-( $f$ ) represent the plasmid DNAs digested with indicated restriction enzymes and blotted onto nitrocellulose sheets. The blots were hybridized with radioactive probes for either the left or the right terminus, to see whether both termini shared common sequences. For each plasmid, the probe was chosen among the smallest terminal fragments available. All the experiments were repeated using the two different procedures of terminal labelling with similar results. (a) pWR1A was digested with Xbal (lane 1) and Pstl (lane 2); the blot was hybridized with the pWR1A left terminal Pstl $0.7 \mathrm{~kb}$ fragment (labelled by random-priming). (b) pWR1B was digested with Ncol (lane 3) and Stul (lane 4); the blot was hybridized with the pWR1B right terminal Stul 2.1 kb fragment (labelled by random-priming). (c) PPE1A was digested with EcoRV (lane 5) and Pstl (lane 6); the blot was hybridized with the pPE1A left terminal ECoRV $0.8 \mathrm{~kb}$ fragment (labelled by Klenow end-filling). (d) pPE1B was digested with HindIII (lane 7) and EcoRI (lane 8); the blot was hybridized with the pPE1B right terminal HindIII $1.8 \mathrm{~kb}$ fragment (labelled by Klenow end-filling). (e) pDH1A was digested with Xhol (lane 9) and Bg/ll (lane 10); the blot was hybridized with the pDH1A right terminal Xhol $0.6 \mathrm{~kb}$ fragment (labelled by Klenow end-filling). ( $f$ ) $\mathrm{pDH} 1 \mathrm{~B}$ was digested with Ncol (lane 11) and Xbal (lane 12); the blot was hybridized with the pDH1B right terminal Xbal $1.5 \mathrm{~kb}$ fragment (labelled by Klenow end-filling). In all cases, two bands were detected which corresponded to the left and right terminal fragments shown in the restriction maps in Fig. 2.

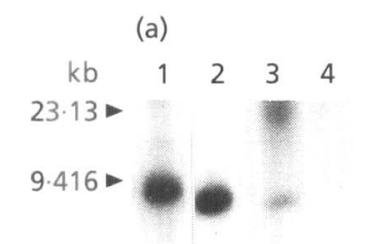

(b)

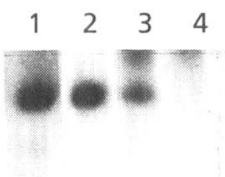

(c)

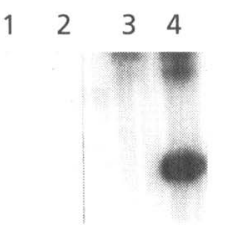

(d)

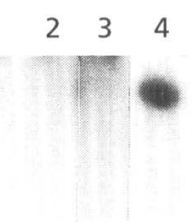

(e)

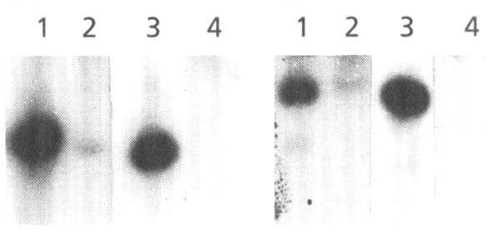

Fig. 5. Sequence homology between plasmids. The plasmids in each strain were separated by gel electrophoresis of colony lysates, and blotted onto a membrane. The blotted DNAs were hybridized, pairwise, with each of the labelled plasmids to detect homology between plasmid sequences. All the combinations were not exposed for the same length of time for autoradiography, because the homologous hybrids had to be exposed for a short time, whilst some heterologous combinations required a much longer time of exposure. The smears near the upper edge of the photographs are the tail of the large host cell DNA band. In each panel, the four lanes represent the colony lysate blots: $K$. lactis (1), W. robertsiae (2), D. hansenii (3) and $P$. etchellsii (4). In panels (a)-(f), individually labelled plasmids were used as probes for hybridization: pWR1A (a), pWR1B (b), pPE1A (c), pPE1B (d), pDH1A (e) and pDH1B (f). 
Table 1. Summary of sequence homology between plasmids

Probes were the entire plasmids labelled with $\left[\alpha^{-32} \mathrm{P}\right] \mathrm{dC}$ TP by random-priming. They were hybridized with each plasmid immobilized on nitrocellulose after electrophoresis as shown in Fig. 1. + and - indicate the presence or absence, respectively, of detectable hybridization under the conditions specified in Methods.

\begin{tabular}{|c|c|c|c|c|c|c|c|c|c|}
\hline \multirow[t]{2}{*}{ Plasmid } & & \multicolumn{8}{|c|}{ Labelled probes } \\
\hline & & PGKL1 & pGKL2 & pDH1A & pDH1B & pWR1A & pWR1B & PPE1A & pPE1B \\
\hline \multirow{2}{*}{$\begin{array}{l}K . \text { lactis } \\
\quad(\text { CBS 2359) }\end{array}$} & pGKL1 & + & - & + & - & + & - & - & - \\
\hline & pGKL2 & - & + & - & + & - & + & - & - \\
\hline \multirow{2}{*}{$\begin{array}{l}\text { K. lactis* } \\
\quad \text { (CBS 1065) }\end{array}$} & pKL2A & + & - & & & & & & \\
\hline & $\mathrm{pKL} 2 \mathrm{~B}$ & - & + & & & & & & \\
\hline \multirow{2}{*}{$\begin{array}{r}W . \text { robertsiae } \\
\text { (CBS 6693) }\end{array}$} & pWR1A & & & + & - & + & - & - & - \\
\hline & pWR1B & & & - & + & - & + & - & - \\
\hline \multirow{2}{*}{$\begin{array}{l}\text { D. bansenii } \\
\text { (CBS 770) }\end{array}$} & $\mathrm{pDH} 1 \mathrm{~A}$ & & & + & - & + & - & - & - \\
\hline & $\mathrm{pDH} 1 \mathrm{~B}$ & & & - & + & - & + & - & $+1-$ \\
\hline \multirow{2}{*}{$\begin{array}{l}\text { P. etchellsii } \\
\quad \text { (CBS 2011) }\end{array}$} & pPE1A & & & - & - & - & - & + & - \\
\hline & pPE1B & & & - & - & - & - & - & + \\
\hline
\end{tabular}

* Results with pKL3A, B, pKL4A, B and pKL5A, B were similar to pKL2A, B.

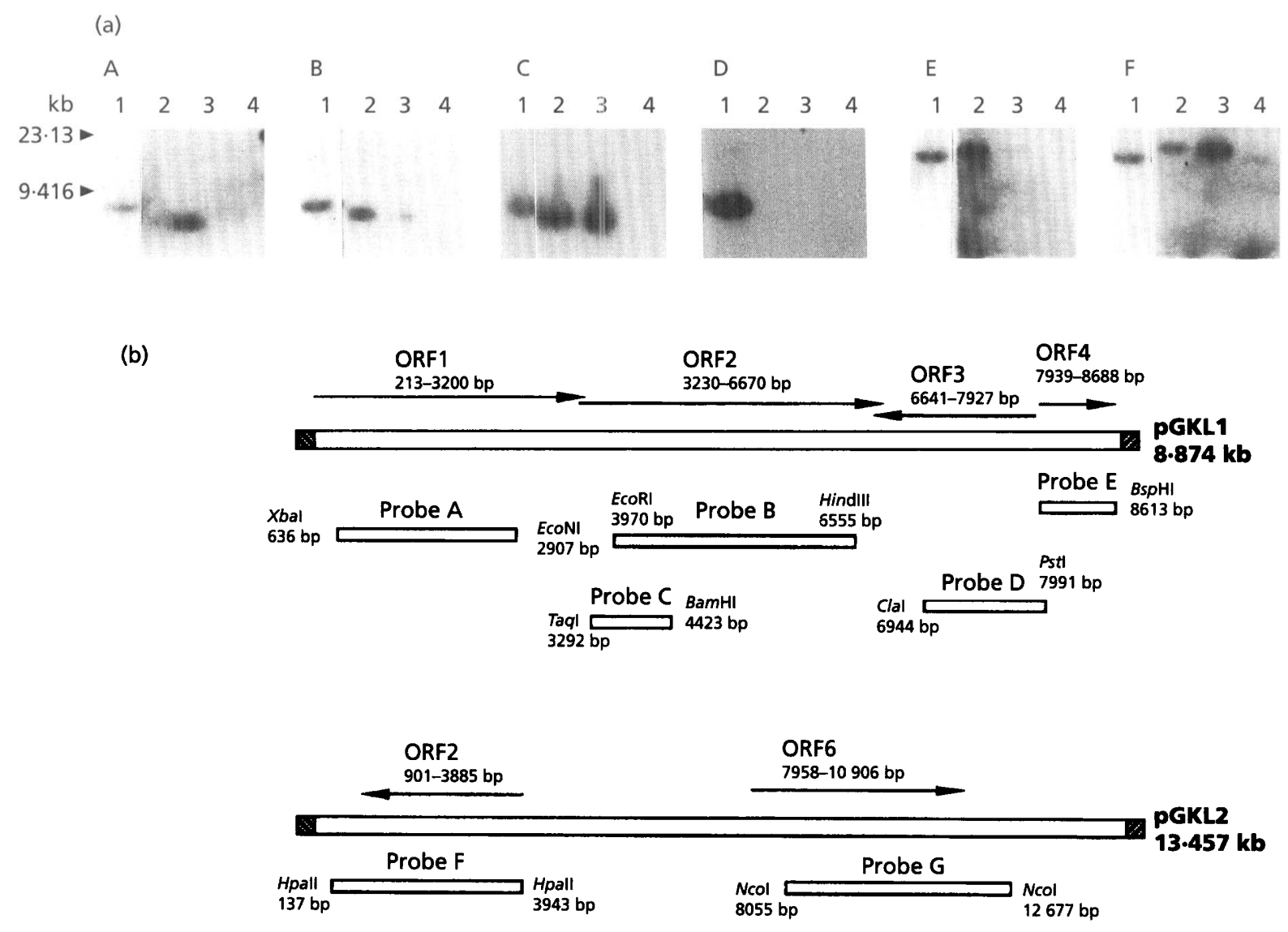

Fig. 6. Homologous sequences in the linear plasmids. (a) Colony lysates from the four species were electrophoresed on agarose gel and blotted to nitrocellulose membranes as described in the legend to Fig. 5. Lanes: 1, K. lactis; 2, W. robertsiae; $3, D$. hansenii; and 4, P. etchellsii. The blots were hybridized with each of the $K$. lactis plasmid gene probes, A-G are as defined in the diagram shown in (b). (b) Position of each probe sequence in the PGKL plasmid genomes. The plasmid maps are based on Sor \& Fukuhara (1985) and Tommasino et al. (1988). 
Table 2. Presence of sequences homologous to PGKL plasmid genes in the new plasmids

On the basis of the series of hybridization experiments illustrated in Fig. 6, the presence of the regions homologous to the pGKL plasmid genes are indicated for each plasmid. ORF2a indicates the chitinase-encoding segment of ORF2. + and - indicate significant and non-significant hybridization, respectively. The experiment with probe E, not represented in Fig. 6, gave a result very similar to the experiment with probe $\mathrm{D}$.

\begin{tabular}{|c|c|c|c|c|c|c|c|}
\hline \multirow[t]{4}{*}{ Plasmid } & \multicolumn{5}{|c|}{ Probes from pGKL1 } & \multirow{2}{*}{\multicolumn{2}{|c|}{$\begin{array}{c}\text { Probes from } \\
\text { pGKL2 }\end{array}$}} \\
\hline & \multirow{3}{*}{$\begin{array}{c}\text { A } \\
\text { ORF1 }\end{array}$} & \multirow{3}{*}{$\begin{array}{c}\text { B } \\
\text { ORF2 }\end{array}$} & \multirow{3}{*}{$\begin{array}{c}\text { C } \\
\text { ORF2a }\end{array}$} & \multirow{3}{*}{$\begin{array}{c}\text { D } \\
\text { ORF3 }\end{array}$} & \multirow{3}{*}{$\begin{array}{c}\text { E } \\
\text { ORF4 }\end{array}$} & & \\
\hline & & & & & & $\mathbf{F}$ & G \\
\hline & & & & & & ORF2 & DRF6 \\
\hline pGKL.1 & + & + & + & + & + & - & - \\
\hline pGKI.2 & - & - & - & - & - & + & + \\
\hline pWR1A & - & + & + & - & - & - & - \\
\hline pWR1B & - & - & - & - & - & + & + \\
\hline $\mathrm{pDH} 1 \mathrm{~A}$ & + & + & + & - & - & - & - \\
\hline pDH1B & - & - & - & - & - & + & + \\
\hline pPE1A & - & - & - & - & - & - & - \\
\hline pPE1B & - & - & - & - & - & - & + \\
\hline
\end{tabular}

of which a few have the sequence motifs characteristic of known functions. Several of these ORF sequences were used as hybridization probes. Examples of these experiments are shown in Fig. 6. The assembled results are summarized in Table 2.

In pGKL1, ORF1 is believed to encode a DNA polymerase (Jung et al., 1987; Fukuhara, 1987), and ORF2 the precursor protein of $\alpha$ and $\beta$ subunits of the toxin (Stark $\&$ Boyd, 1986). The $\alpha$ subunit has been shown to be a chitinase (Bradshaw, 1990; Butler et al., 1991a). The function of the $\beta$ subunit is unknown. ORF3 encodes a toxin-resistance determinant (Tokunaga et al., 1987) and ORF4 the toxin $\gamma$ subunit (Stark \& Boyd, 1986) which is thought to be responsible for the killing action of the toxin (Tokunaga et al., 1989; Butler et al., 1991b). In pGKL2, ORF2 probably encodes a DNA polymerase (Tommasino et al., 1988) and ORF6 a RNA polymerase (Wilson \& Meacock, 1988).

These coding sequences were individually excised from the killer plasmids, labelled and hybridized with the new plasmid DNAs blotted on nitrocellulose membranes. Some of the results are illustrated in Fig. 6. pDH1A and pWR1A clearly contained the sequence homologous to the putative DNA polymerase gene of pGKL1. These two plasmids also contained sequences homologous to the ORF2 gene of pGKL1. Within this ORF2, the chitinase gene sequence segment appears to be the major source of the homology signal. The ORF4 probe $(\gamma$ subunit gene) did not hybridize with any of the new plasmids. The putative DNA and RNA polymerase genes from pGKL2 specifically hybridized with $\mathrm{pDH} 1 \mathrm{~B}$ and pWR1B plasmids, suggesting that these large DNA components in the double plasmid system have a role analogous to that of pGKL2 in the K. lactis killer system. For example, gene expression in both large and small plasmids should rely on the RNA polymerase from the large plasmid. With pPE1 plasmids, a detectable hybridization was observed only between pPE1B and the pGKL2 ORF6 probe (the supposed RNA polymerase gene).

\section{Killer activity of the plasmids}

No killer activity has been detected so far in the strains harbouring pDH1, pWR1 or pPE1 plasmids. They were tested at $20^{\circ} \mathrm{C}$ and $28{ }^{\circ} \mathrm{C}$ against $S$. cerevisiae, $K$. lactis and C. glabrata. Obviously this result does not exclude the possibility that the plasmids produce a toxin that is active on other untested yeasts. Although there is no rationale for the search of such target strains, the studies on known killer systems have shown that the strains harbouring the killer plasmids generally become toxin-sensitive when cured of the plasmids. Therefore, the three strains, CBS 770 , CBS 6693 and CBS 2011, were treated with ultraviolet light. Many clones cured of the plasmids were obtained (see Methods). The plasmid-less strains were submitted to the killer test against the original plasmid-carrier strains. None of the plasmid-less derivatives showed a zone of growth inhibition around the colonies of the plasmid carriers.

The three strains carrying plasmids were also tested for their sensitivity to the $K$. lactis killer toxin. The P. etchellsii strains, whether cured of the plasmids or not, were sensitive to the toxin. The $W$. robertsiae and $D$. bansenii strains were resistant. This resistance is not due to the presence of the plasmids, however, because after curing of the plasmids these yeasts remained resistant to the toxin.

\section{DISCUSSION}

A systematic survey of about 1400 strains covering about $80 \%$ of the currently accepted species of yeast revealed the presence of several new linear DNA plasmids. Plasmids similar to the pGKL killer plasmids were found in four different isolates of $K$. lactis, but not in other species. In the three yeast species reported here, the newly found plasmids also showed several features related to the $K$. lactis killer plasmids, although killer activity was not detected in these cases. The features common to all these plasmids were (i) their presence in the host cell as a pair of linear double-stranded DNA molecules, (ii) presence of homologous sequences at the right and left ends of the molecule, and (iii) the blocked $5^{\prime}$ ends. In all cases, the copy number, judged by ethidium bromide staining, appears to be as high as that of the pGKL plasmids which had previously been estimated to be about 50-70 copies per cell (Wésolowski et al., 1982).

At the DNA sequence level, the plasmids from $D$. bansenii and $W$. robertsiae are clearly related to the pGKL plasmids. Both the small and large DNA units shared homologous sequences. However, this homology was not dispersed along the plasmid genome, but appeared to be restricted to certain genes. Sequences related to the putative DNA 
polymerase gene and the chitinase gene of pGKL1 were detected in the small DNA components. In the large DNA components, there were sequences related to the putative DNA polymerase gene as well as the RNA polymerase gene of pGKL2. Neither the toxin $\gamma$ subunit gene nor the toxin resistance gene of the pGKL1 plasmid were detectable. The plasmids from $P$. etchellsii retained none of the pGKL plasmid sequences, except for pPE1B which contained the RNA polymerase-like sequence of pGKL2.

The present study shows that linear DNA plasmids can be found among various yeast species, although the number of confirmed cases is still few. With the exception of those of $K$. lactis strains, none of these plasmids had an identified killer activity. However, the sequence of their DNA often matches parts of the pGKL plasmids. In each case, the small plasmid components shared homology with pGKL1 and the large components with pGKL2. This suggests that the partition of various functions between the pair of plasmids in $W$. robertsiae and $D$. bansenii may be analogous to the pGKL plasmid system. Regarding the nature of the genes present in pPE1A and B of $P$. etchellsii, no speculation can be made as they show little homology with all other plasmids. However, the sum of our findings suggests that, despite a great divergence of individual sequences, the basic modular architecture of each plasmid is conserved among the yeast linear plasmids. It is known that in the $2 \mu \mathrm{m}$ circular plasmid family of yeasts (about a dozen are known; see Chen et al., 1992), individual gene sequences diverge widely, but their functions and positions in the plasmid genome are conserved.

The presence of related linear plasmids in the three species of yeast described here might suggest the possibility that these yeasts are closely related species, because horizontal propagation of linear plasmids would preferentially occur between related species. However, these species are not closely related in their chromosomal sequences according to the reported GC contents of nuclear DNA: D. bansenii 38.2-38.6 mol\% (Kreger-van Rij, 1984), W. robertsiae $42.7 \mathrm{~mol} \%$ and P. etchellsii $40 \cdot 6 \mathrm{~mol} \%$ (Price et al., 1978).

The presence of a chitinase-related gene sequence in these non-killer plasmids is intriguing. In the $K$. lactis killer system, the chitinase is supposed to help the toxin protein to penetrate the target cells. If $\mathrm{pWR} 1$ and $\mathrm{pDH} 1$ plasmids are proved to be producing an active chitinase, we may suspect that it accompanies a yet unknown toxin which had replaced the $K$. lactis toxin. Proteins secreted into the media by these species are currently being examined.

A few other linear plasmids have been identified in yeast. Saccharomycopsis crataegensis (NRRL Y-5902) contained three linear plasmids, pScr1-1, pScr1-2 and pScr1-3 (Shephard et al., 1984). They have blocked $5^{\prime}$ ends and reside in the cytoplasm. A strain of $P$. inositovora (NRRL Y-12698) has also been reported to contain linear DNA plasmids (pPin1-1, pPin1-2 and pPin1-3) (Ligon et al., 1989). None of the plasmids were associated with a killer activity. Worsham \& Bolen (1990) have reported that the killer activity of $P$. acaciae (NRRL Y-18665) against $D$. tamarii (now identified as $C$. versatilis) was due to the presence of linear DNA plasmids (pPac1-1 and pPac1-2). In none of these cases was the homology of the DNA with that of the plasmids of $K$. lactis determined. Such information will help to give a general view on the origin and relationship of the various components that form the family of linear DNA plasmids.

In a recent publication, Gunge et al. (1993) reported that a strain of $D$. hansenii contained three linear plasmids (pDHL1, 2 and 3;8.4, 9.2 and $15.0 \mathrm{~kb}$, respectively). As judged from their molecular sizes and restriction maps, they are clearly different from the $\mathrm{pDH} 1 \mathrm{~A}$ and $\mathrm{B}$ plasmids described here. pDHL plasmids were reported to be unstable at low osmotic pressure. pDH1 $\mathrm{A}$ and $1 \mathrm{~B}$ are not.

\section{ACKNOWLEDGEMENTS}

Y.-S.C. received a fellowship from the Government of the People's Republic of China. This work was supported in part by the Commission of the European Communities (BIOT-CT910267).

\section{REFERENCES}

Bradshaw, H. D. (1990). Killer toxins. Nature 345, 299.

Butler, A. R., O'Donnel, R. W., Martin, V. J., Gooday, G. W. \& Stark, M. J. R. (1991a). Kluyveromyces lactis toxin has an essential chitinase activity. Eur J Biochem 199, 483-488.

Butler, A. R., Porter, M. \& Stark, M. J. R. (1991b). Intracellular expression of Klyyveromyces toxin gamma subunit mimics treatment with exogenous toxin and distinguishes two classes of toxinresistant mutants. Yeast 7, 617-625.

Chen, X. J., Cong, Y. S., Wésolowski-Louvel, M., Li, Y. Y. \& Fukuhara, H. (1992). Characterization of a circular plasmid from the yeast Kluyveromyces waltii. J Gen Microbiol 138, 337-345.

Dinouël, N., Drissi, R., Miyakawa, I., Sor, F., Rousset, S. \& Fukuhara, H. (1993). Linear mitochondrial DNA of yeasts. Closed loop structure of the termini and possible linear-circular conversion mechanisms. Mol Cell Biol 13, 2309-2314.

Fukuhara, H. (1987). The RF1 gene of the killer DNA of yeast may encode a DNA polymerase. Nucleic Acids Res 15, 10046.

Gunge, N. (1986). Linear DNA killer plasmids from the yeast Kluyveromyces. Yeast 2, 115-162.

Gunge, N., Tamaru, A., Ozawa, F. \& Sakaguchi, K. (1981). Isolation and characterization of linear deoxyribonucleic acid plasmids from Kluyveromyces lactis and the plasmid-associated killer character. I Bacteriol 145, 382-390.

Gunge, N., Fukuda, K., Morikawa, S., Murakami, K., Takeda, M. \& Miwa, A. (1993). Osmophilic linear plasmids from the salt-tolerant yeast Debaryomyces bansenii. Curr Genet 23, 443-449.

Hara, S. (1985). Killer yeasts and killer toxins. Kagaku to Seibutsu 23, 151-161 (in Japanese).

Hishinuma, F., Nakamura, K., Hirai, K., Nishizawa, R., Gunge, N. \& Maeda, T. (1984). Cloning and nucleotide sequences of the linear killer plasmids from yeast. Nucleic Acids Res 12, 7581-7587.

Jung, G., Leavitt, M. C. \& Ito, J. (1987). Yeast killer plasmid pGKL1 encodes a DNA polymerase belonging to the family of $B$ DNA polymerase. Nucleic Acids Res 15, 9088.

Kikuchi, Y., Hirai, K. \& Hishinuma, F. (1984). The yeast linear DNA killer plasmids, pGKL1 and pGKL2, possess terminally attached proteins. Nucleic Acids Res 12, 5685--5692.

Kitada, K. \& Hishinuma, F. (1987). A new linear DNA plasmid 
isolated from the yeast Saccbaromyces kluyveri. Mol \& Gen Genet 206, $377-381$.

Kreger-van Rij, N. J. W. (ed.) (1984). The Yeasts. A Taxonomic Study, 3rd edn. Amsterdam: Elsevier.

Ligon, J. M., Bolen, P. L., Hill, D. S., Bothast, R. J. \& Kurtzman, C. P. (1989). Physical and biological characterization of linear plasmids of the yeast Pichia inositovora. Plasmid 21, 185-194.

Meinhardt, F., Kempken, F., Kämper, J. \& Esser, K. (1990). Linear plasmids among eukaryotes: fundamentals and application. Curr Genet 17, 89-95.

Price, C. W., Fuson, G. B. \& Phaff, H. J. (1978). Genome comparison in yeast systematics: delimitation of species within the genera Scbwanniomyces, Saccharomyces, Debaryomyces and Pichia. Microbiol Rev 42, 161-193.

Shepherd, H. S., Ligon, J. M., Bolen, P. L. \& Kurtzman, C. P. (1984). Cryptic DNA plasmids of the heterothallic yeast Saccharomycopsis crataegensis. Curr Genet 12, 297-304.

Sor, F. \& Fukuhara, H. (1985). Structure of a linear plasmid of the yeast Kliyveromyces lactis: compact organization of the killer genome. Curr Genet 9, 147-155.

Sor, F., Wésolowski-Louvel, M. \& Fukuhara, H. (1983). Inverted terminal repetitions of the two linear DNA associated with the killer character of the yeast Kluyveromyces lactis. Nucleic Acids Res 11, 5037-5044.

Stam, J. C., Kwakman, J., Meijer, M. \& Sutuitje, A. R. (1986). Efficient isolation of the linear plasmids of Kluyveromyces lactis: evidence for location and expression in the cytoplasm and characterization of their terminally bound proteins. Nucleic Acids Res 14, 6871-6884.

Stark, M. J. R. (1988). Resolution of sequence discrepancies in the ORF1 region of the Kluyveromyces lactis plasmid k1. Nucleic Acids Res 16, 771 .
Stark, M. J. R. \& Boyd, A. (1986). The killer toxin of Kluyveromyces lactis: characterization of the toxin subunits and identification of the genes which encode them. EMBO J 5, 1995-2002.

Stark, M. J. R., Mileham, A. J., Romanos, M. A. \& Boyd, A. (1984). Nucleotide sequence and transcription analysis of a linear DNA plasmid associated with the killer character of the yeast Kluyveromyces lactis. Nucleic Acids Res 12, 6011-6030.

Stark, M. J. R., Boyd, A., Mileham, A. J. \& Romanos, M. A. (1990). The plasmid-encoded killer system of Kluyveromyces lactis: a review. Yeast 6, 1-29.

Tokunaga, M, Wada, N. \& Hishinuma, F. (1987). Expression and identification of immunity determinant on linear DNA killer plasmids pGKL1 and PGKL2 in Kluyveromyces lactis. Nucleic Acids Res 15, 1031-1046.

Tokunaga, M., Kawamura, A. \& Hishinuma, F. (1989). Expression of pGKL killer $28 \mathrm{~K}$ subunit in $S$. cerevisiae: identification of $28 \mathrm{~K}$ subunit as a killer protein. Nucleic Acids Res 17, 3435-3446.

Tommasino, M., Ricci, S. \& Galeotti, C. L. (1988). Genome organization of the killer plasmid pGKL2 from Kluyveromyces lactis. Nucleic Acids Res 16, 5863-5877.

Wésolowski, M., Algeri, A. A., Goffrini, P. \& Fukuhara, H. (1982). Killer DNA plasmids of the yeast Kluyveromyces lactis. I. Mutations affecting the killer phenotype. Curr Genet 5, 191-197.

Wilson, D. W. \& Meacock, P. A. (1988). Extranuclear gene expression in yeast: evidence for a plasmid-encoded RNA polymerase of unique structure. Nucleic Acids Research 16, 8097-8112.

Worsham, P. L. \& Bolen, P. L. (1990). Killer toxin production in Pichia acaciae is associated with linear DNA plasmids. Curr Genet 18, 77-80.

Received 25 June 1993; revised 29 September 1993; accepted 20 December 1993. 